\section{Final FRCR 2B Viva: A Survival Guide}

K.T. Tan, J. Curtis, and J. Aw, eds.

New York, NY: Cambridge University Press, 2012, 607 pages, $\$ 75.00$

This paperback was derived from An Aid to the MRCP Short Cases by Ryder, Mir, and Freeman, a book that helps with preparation for the stressful MRCP (Membership of the Royal Colleges of Physicians) examination. Final FRCR $2 B$ Viva: A Survival Guide was prepared by radiologists in Britain, Australia, and North America with a passion for education and a talent for condensing key information into a succinct and useful format.

The focus of the book is to help prepare radiologist trainees for their final oral (viva voce) FRCR examination (Fellow of the Royal College of Radiologists) by providing a series of viva examination-type cases that comprehensively review most of what the competent radiology graduate needs to know. The book is organized into 7 chapters according to organ systems and includes 263 cases: 44 cardiothoracic, 6 vascular, 44 gastrointestinal, 49 musculoskeletal, 49 neurologic, 17 genitourinary, 9 breast, 25 pediatric radiology, and 20 nuclear medicine. For each case, a presentation is provided to act as a template.

The content of the book is based on updated reviews, with many fine examples of conventional imaging and presentation of stateof-the-art studies that illustrate the timeless principles of diagnostic radiology. Facts that are clinically important but not readily available in common textbooks are included in the text. The text for each case is presented as one would approach the subject in the viva examination, with the description followed by crucial clinical questions and a brief discussion with suggestions for further reading. The images are of high quality, are representative of both common and important unusual conditions, and are accompanied by clear and concise explanations, enabling trainees to prepare fully for their examination.

Clinically important vignettes are provided to help the reader impress examiners and colleagues and acquire the ability to come up with differential diagnoses. The text is an enjoyable read and provides an opportunity to confirm what is known and to determine which areas may require some additional attention. Those seeking continuing medical education on radiology through a nonconfrontational method of self-evaluation will also find the book useful.

\section{E. Edmund Kim}

M.D. Anderson Cancer Center

1400 Pressler, Unit 1483

Houston, TX 77030

E-mail: ekim@mdanderson.org

Published online Aug. 29, 2012.

DOI: $10.2967 /$ jnumed.112.112383

\section{Nuclear Medicine Board Review: Questions and Answers for Self-Assessment}

C.R. Goldfarb, S.R. Parmett, L.S. Zuckier, F. Ongseng, M. Karam, and M.R. Chamarthy, eds.

New York, NY: Thieme, 2012, 208 pages, \$49.99

Nuclear medicine remains a major subsection of the American Board of Radiology examination and has been appearing more frequently on certification examinations in other medical specialties. The American Board of Nuclear Medicine now mandates yearly learning and involvement in a self-assessment process in addition to the maintenance-of-certification examination every $10 \mathrm{y}$ for its diplomates from 1992 onward.

Since the publication of the second edition of Nuclear Medicine Board Review, nuclear medicine has experienced significant evolution and growth. PET/CT has become the standard of oncologic care, SPECT/CT is growing in parallel, and PET/MRI will soon become a clinical tool. Radionuclide treatment has always been a core feature of nuclear medicine, and radioimmunotherapy or radiopeptide therapy is on the verge of substantial expansion.

This third edition adds hundreds of questions designed to encompass these developments, speed the grasping of relevant information, and enhance retention. However, the convenient question-and-answer format of the second edition has been retained. New appendices have been introduced and include terse tips for test takers, instant essentials for image interpreters, and must-know concepts, along with cases and calculations for everyone.

This book is organized into 4 chapters with 2,111 questions and answers. Chapter 1, with 272 questions, deals with the essentials of nuclear medicine. Chapter 2, with 1,416 questions, discusses singlephoton applications. Chapter 3, with 398 questions, handles PET/CT. Finally, chapter 4, with 25 questions, deals with radionuclide therapy.

This concise text is ideal for all who need a quick and efficient review for the board examination. It is also a handy reference for residents, clinicians, and technologists, as it contains updated coverage of all major advances in nuclear medicine and molecular imaging.

E. Edmund Kim

M.D. Anderson Cancer Center

1400 Pressler, Unit 1483

Houston, TX 77030

E-mail:ekim@mdanderson.org

Published online Aug. 31, 2012. DOI: 10.2967/jnumed.112.112391

COPYRIGHT @ 2012 by the Society of Nuclear Medicine and Molecular Imaging, Inc. 